\title{
IMPACTO DE Guadua paraguayana SOBRE REMANESCENTE DE FLORESTA OMBRÓFILA MISTA ALUVIAL - UMA ABORDAGEM BIOGEOQUÍMICA
}

\author{
Franklin Galvão ${ }^{1}$, Cátia Regina Augustin ${ }^{2}$, Gustavo Ribas $\mathrm{Curcio}^{3}$, Nelson Cosmo ${ }^{4}$, Carina Kozera ${ }^{5}$, \\ Bruno Polli Domanowski ${ }^{6}$, Alison Tadeu Sawczuk ${ }^{6}$ \\ ${ }^{1}$ Eng. Florestal, Dr., Depto. de Ciências Florestais, UFPR, Curitiba, PR, Brasil - fgalvao@ufpr.br \\ ${ }^{2}$ Eng $^{\mathrm{a}}$ Florestal, Mestranda em Engenharia Florestal, UFPR, Curitiba, PR, Brasil - catiaraugustin@ gmail.com \\ ${ }^{3}$ Eng. Agrônomo, Dr., Embrapa Florestas, Colombo, PR, Brasil - curcio@ cnpf.embrapa.br \\ ${ }^{4}$ Eng. Florestal, M.Sc., Doutorando em Engenharia Florestal, UFPR, Curitiba, PR, Brasil - ncosmo@ gmail.com \\ ${ }^{5}$ Bióloga, Dra ${ }^{\mathrm{a}}$, UFPR, Campus Palotina, Palotina, PR, Brasil - carinakozera@ yahoo.com.br \\ ${ }^{6}$ Eng. Florestal, UFPR, Curitiba, PR, Brasil - brunopolli@ hotmail.com; alison.tadeu@gmail.com
}

Recebido para publicação: 17/11/2010 - Aceito para publicação: 09/03/2012

\begin{abstract}
Resumo
Guadua paraguayana Döll, um bambu nativo da porção meridional da América do Sul particularmente agressivo, está invadindo áreas de preservação permanente no segundo planalto paranaense, com supressão da vegetação instalada e modificações nos padrões de sucessão local. Após estabelecer sua autoecologia, para melhor avaliar seu impacto sobre um dos últimos remanescentes da Floresta Ombrófila Mista Aluvial (FOMA), principalmente na ciclagem de nutrientes e no fluxo de carbono orgânico para o ambiente, estudou-se a composição química da espécie, a produção e decomposição de serapilheira e a distribuição das raízes. A área em estudo (25 13 '20,8” S e 5004'26,8” W, Ponta Grossa/PR) é uma planície de inundação degradada às margens do rio Tibagi. Os valores anuais de produção de serapilheira de G. paraguayana foram estimados em $7.500 \mathrm{~kg} / \mathrm{ha}$, com meia vida superior a 260 dias para os limbos e 360 dias para as bainhas foliares. No período analisado, as folhas retornaram ao ambiente $164,27 \mathrm{~kg} / \mathrm{ha}$ de macronutrientes. Com base na concentração de carbono da folha, o fluxo de carbono orgânico da vegetação para o solo foi estimado em $2.800 \mathrm{~kg} / \mathrm{ha} / \mathrm{ano}$. Em comparação com os valores de FOMA melhor preservada, a presença dominante desse bambu reduz a quantidade de nutrientes e de carbono devolvidos ao meio.

Palavras-chave: Bambu; serapilheira; ciclagem de nutrientes.
\end{abstract}

Abstract

Guadua paraguayana's impacts on a remaining of Subtropical Ombrophilous Alluvial Forest - a biogeochemistry approach. Guadua paraguayana Döll, a particularly aggressive native bamboo from the southern portion of South America, is invading permanent preservation areas located in the second plateau of Parana, causing suppression of the current vegetation and modifications in the local succession patterns. After determine its autecology, to better assess its impact on one of the last remaining of Subtropical Ombrophilous Alluvial Forest, mainly on nutrient cycling and organic carbon flux to the environment, it was studied the species' chemical composition and the production and decomposition of litter, and roots distribution. The focused area (25 13 '20.8' S and 50 04 '26.8" W, Ponta Grossa-PR, BR) is a degraded floodplain of Tibagi river. The annual litter production values of $G$. paraguayana were estimated at $7,500 \mathrm{~kg} / \mathrm{ha}$, with a half-life of more than 260 days for the blades and 360 days for the sheaths. Within this period, the photosynthetic leaves returned to the environment (bars) $164.27 \mathrm{~kg} / \mathrm{ha}$ of macronutrients. Based on the concentration of carbon in the leaf, the flux of organic carbon from vegetation to soil was estimated at $2,800 \mathrm{~kg} / \mathrm{ha} / \mathrm{year}$. The dominant presence of bamboo in the area decreases the amount of carbon and nutrients returned to the environment, when confronted with Subtropical Ombrophilous Alluvial Forest better preserved.

Keywords: Bamboo; litter; nutrient cycling.

\section{INTRODUÇÃO}

Frágeis por vários fatores inerentes à formação, os ambientes ripários têm enfrentado, e muitas vezes perdido, uma difícil batalha contra a ocupação humana. 
No segundo planalto paranaense, no espaço destinado a abrigar o Refúgio de Vida Silvestre do Rio Tibagi, Unidade de Conservação federal destinada a preservar o pouco que resta da Floresta Ombrófila Mista Aluvial (FOMA) (MINISTÉRIO DE MEIO AMBIENTE (MMA) s.d.), a pressão antrópica surge das áreas adjacentes - pelo desmatamento das margens, plantio intensivo de soja e trigo, erosão causada por técnicas inapropriadas de cultivo e contaminação por agrotóxicos e fertilizantes -, e pelo leito do rio, com a tradicional mineração de areia proporcionada pela litologia local (arenito Furnas).

Recentemente, esses remanescentes florestais passaram a sofrer também um embate interespecífico, apesar de a causa indireta ainda estar na degradação ambiental. Uma espécie nativa (OHMBERGER, 1999; FILGUEIRAS; GONÇALVES, 2004) de bambu, Guadua paraguayana Döll (Poaceae, Bambusoideae), tem alterado significativamente a paisagem, provocando redução na densidade e vitalidade dos demais indivíduos estabelecidos, do sub-bosque, do epifitismo e da regeneração às margens do rio (GALVÃO et al., prelo).

Para avaliar a repercussão da presença desse bambu sobre a vegetação local, complementou-se o estudo de sua autoecologia (GALVÃO et al., 2009) com a análise da distribuição das raízes e foram determinadas sua composição química e a produção e decomposição de sua serapilheira.

\section{REVISÃO BIBLIOGRÁFICA}

\section{Rio Tibagi}

O Tibagi forma a terceira maior bacia hidrográfica do estado do Paraná. Nasce no município de Ponta Grossa (arenito Furnas) e tem sua foz ao norte, no rio Paranapanema, fronteira com São Paulo. São 616 km de curso. Vivem, em sua área de influência, mais de um milhão e duzentas mil pessoas (INSTITUTO PARANAENSE DE DESENVOLVIMENTO ECONÔMICO E SOCIAL (IPARDES), 2008).

Os remanescentes florestais ao longo de suas margens foram reduzidos a fragmentos de viabilidade duvidosa por equívocos no uso agrícola do solo, desmatamento, urbanização crescente e, no terço superior do rio, pelos mais de 50 anos de mineração de areia em seu leito.

As alterações na modelagem da planície aluvial, ao destruírem o conjunto de condições que dava vantagens às espécies nativas da FOMA, possibilitaram a propagação de espécies agressivas e oportunistas, como os bambus.

\section{Floresta ripária - aspectos pedológicos e funcionais}

Por serem conformadas pela heterogeneidade típica desses ambientes (variações edáficas, topográficas, de encharcamento do solo, das formações vegetais em torno, das características hidrológicas da bacia e do curso d'água), as florestas ripárias (ciliares/ribeirinhas) apresentam muitos pontos em comum onde quer que ocorram.

As flutuações do nível do rio, com consequente remoção ou soterramento da serapilheira, e o transporte, pela chuva, de sedimentos das áreas contíguas, são um exemplo das forças que atuam sobre elas. A ação desses fatores sobre o banco de sementes e o processo de ciclagem acaba por gerar perturbações frequentes na vegetação aí instalada, determinando sua relativa pobreza de espécies (RODRIGUES; SHEPHERD, 2000).

Nas áreas ripárias, os solos variam em função da natureza do material de origem e de um maior ou menor grau de hidromorfismo. Onde a presença de água é permanente, são comuns os Organossolos, Gleissolos e Neossolos Quartzarênicos hidromórficos. Nas porções livres de inundação periódica, predominam os Neossolos Flúvicos e os Cambissolos (JACOMINE, 2000).

Em comum, também, as formações ciliares têm o desempenho de papéis de cunho hidrológico (floresta protegendo o curso d'água) e ecológico (floresta protegendo a biodiversidade).

Em termos de volume hídrico, a vegetação ripária contribui para um aumento da capacidade de armazenamento de água e controle de vazão dos rios. Qualitativamente, a vegetação desempenha, isolando os cursos d'água dos terrenos vizinhos, ação de filtragem dos sedimentos, nutrientes e/ou substâncias tóxicas; estabiliza as margens; fornece matéria orgânica para o solo e para os corpos d'água; garante sombreamento; regula temperatura; proporciona hábitats e exerce, ainda, a função de corredor de fluxo gênico ao longo da paisagem (LIMA; ZAKIA, 2000). 


\section{Guadua paraguayana}

No Brasil, país com a maior diversidade em espécies de bambu das Américas, estão presentes 89\% dos gêneros e 65\% das espécies do Novo Mundo (FILGUEIRAS; GONÇALVES, 2004). Especialistas em tirar vantagens de pequenas ou grandes perturbações ambientais, bambus podem ter um efeito profundo na dinâmica da vegetação de uma área (JUDZIEWICZ et al., 1999), e suas oportunidades de expansão têm, muitas vezes, a marca da mão humana.

O estudo da autoecologia da espécie, realizado por Galvão et al. (2009) na mesma área do presente trabalho, demonstrou que o sucesso no estabelecimento $G$. paraguayana se deve principalmente à degradação ambiental e à estratégia de crescimento desse bambu. Houve, nesse ambiente, por intensa pressão de uso, diminuição da saturação hídrica do solo, com desenvolvimento de condições menos propícias à espécie dominante da FOMA, Sebastiania commersoniana, o branquilho.

O crescimento de G. paraguayana, invasora agressiva, se dá em touceiras formadas pela expansão vigorosa de um único indivíduo. Os colmos, que chegam a $18 \mathrm{~m}$, se lançam sobre o dossel da floresta, provocando forte sombreamento e suprimindo a vegetação instalada, modificando os padrões de sucessão local. A brotação se dá predominantemente no verão. Durante essa fase, o crescimento médio dos colmos é de $18 \mathrm{~cm} /$ dia, podendo atingir picos de $75 \mathrm{~cm} /$ dia (Galvão et al., 2009).

As touceiras então analisadas apresentaram área média de $2,79 \mathrm{~m}^{2}$, com $11 \mathrm{colmos} / \mathrm{m}^{2}$, distribuídos de maneira radial. G. paraguayana possui colmos grandes e maciços com, em média, $13 \mathrm{~m}$ de comprimento e projeção da porção apical com raio de 10 a $12 \mathrm{~m}$. O diâmetro médio dos colmos a $1,30 \mathrm{~m}$ (diâmetro à altura do peito - DAP) é de $4,25 \mathrm{~cm}$.

Como característica de gênero e com função de defesa contra predação, espinhos em forma de garra estão presentes na base dos ramos. Os nós apresentam uma característica faixa de tricomas brancos cuja largura varia proporcionalmente ao diâmetro do colmo, indo de 2,0 a 3,5 cm aproximadamente (Galvão et al., 2009).

\section{Ciclagem}

O desenvolvimento da camada de serapilheira é uma característica particular aos ecossistemas florestais. Sua dinâmica de produção, deposição e decomposição é a principal via de transferência de nutrientes e energia da vegetação para o solo (PRITTCHET, 1986; MELLO, 1995). A velocidade de liberação dos nutrientes é determinante para a manutenção do ecossistema: se for muito elevada, os elementos podem ser lixiviados ou volatilizados; se for baixa, a disponibilidade de minerais pode ser insuficiente e resultar em inibição de crescimento (JORDAN, 1985).

Por descrever um sistema praticamente autoalimentado, ao processo resultante da absorção, assimilação e armazenamento dos nutrientes pela biomassa; do retorno destes ao solo como matéria orgânica ou pelas chuvas; da acumulação e decomposição do material biogênico na superfície do solo; e da liberação de seus componentes minerais, outra vez disponibilizados para serem assimilados pelas plantas, dá-se o nome de ciclagem (MASON, 1980; DELITTI, 1995).

É a ciclagem que regula o funcionamento e o desenvolvimento do ecossistema. Esse processo permite que os nutrientes presentes na serapilheira sejam utilizados em sucessivos períodos de fixação de energia, garantindo produtividade principalmente em ambientes com solos de baixa fertilidade ou fortemente lixiviados (MASON, 1980; DELITTI, 1995).

Há processos de transferência que são exclusivos das florestas ciliares. A entrada, a partir das áreas adjacentes, de sedimentos carregados pelas águas das chuvas ou do rio e retidos pela faixa florestal, que atua como filtro, é o primeiro deles. Há, ainda, a chegada de nutrientes através do fluxo lateral do lençol freático, que transporta os nutrientes das partes altas do terreno para a faixa ciliar. Mas nem tudo que chega permanece. Nas áreas inundáveis, pode haver perda de nutrientes pelo arrastamento da serapilheira pelas águas dos rios (SOUSA, 2003).

Mesmo que nas florestas ciliares o estudo do fluxo de nutrientes seja bastante complexo - as entradas e saídas de nutrientes minerais dependem em grande parte de fatores externos -, a serapilheira é o parâmetro mais estudado em ciclagem. Sua avaliação quantitativa permite a comparação entre ecossistemas (DELITTI, 1995), constituindo um importante instrumento de avaliação de impactos ambientais. 


\section{MATERIAL E MÉTODOS}

\section{Localização e caracterização da área de estudo}

A área de estudo - Ponta Grossa/PR, coordenadas $25^{\circ} 13^{\prime} 20,8^{\prime \prime}$ S e $50^{\circ} 04^{\prime} 26,8^{\prime \prime}$ W - é um remanescente da FOMA em planície fluvial degradada, às margens do rio Tibagi, em zona de amortecimento de quatro Unidades de Conservação: APA da Escarpa Devoniana, Parque Estadual de Vila Velha, Parque Nacional dos Campos Gerais e Refúgio de Vida Silvestre do Rio Tibagi (Figura 1).

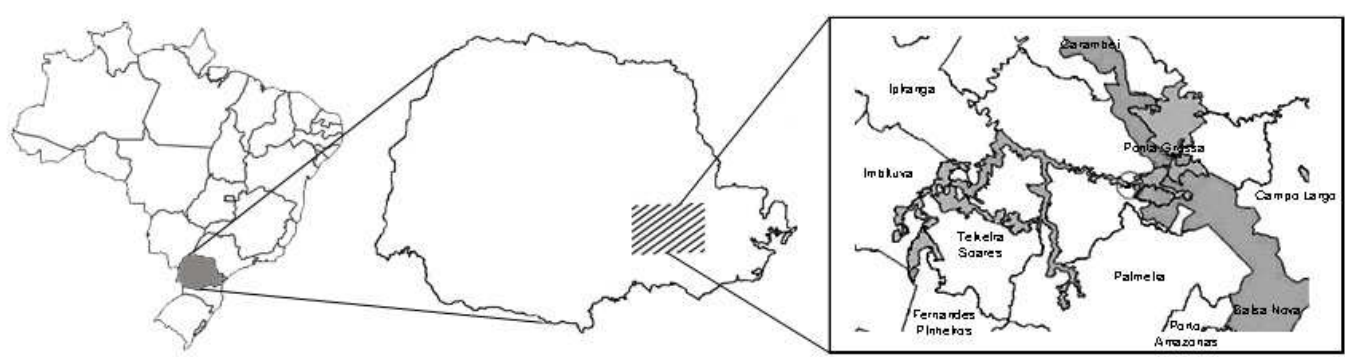

Figura 1. Localização da área de estudo (círculo) com destaque para as unidades de conservação (cinza). Figure 1. Location of the focused area (circle) highlighting the conservation areas (gray).

A planície apresenta feições caracterizadas por barras e interbarras (Figura 2). As regiões alçadas (barras) são constituídas por Neossolos Flúvicos e Cambissolos Flúvicos, e as deprimidas (interbarras), por Gleissolos Háplicos. A litologia local é dominada pelo arenito Furnas (MINERAIS DO PARANÁ S/A - MINEROPAR, 1989).

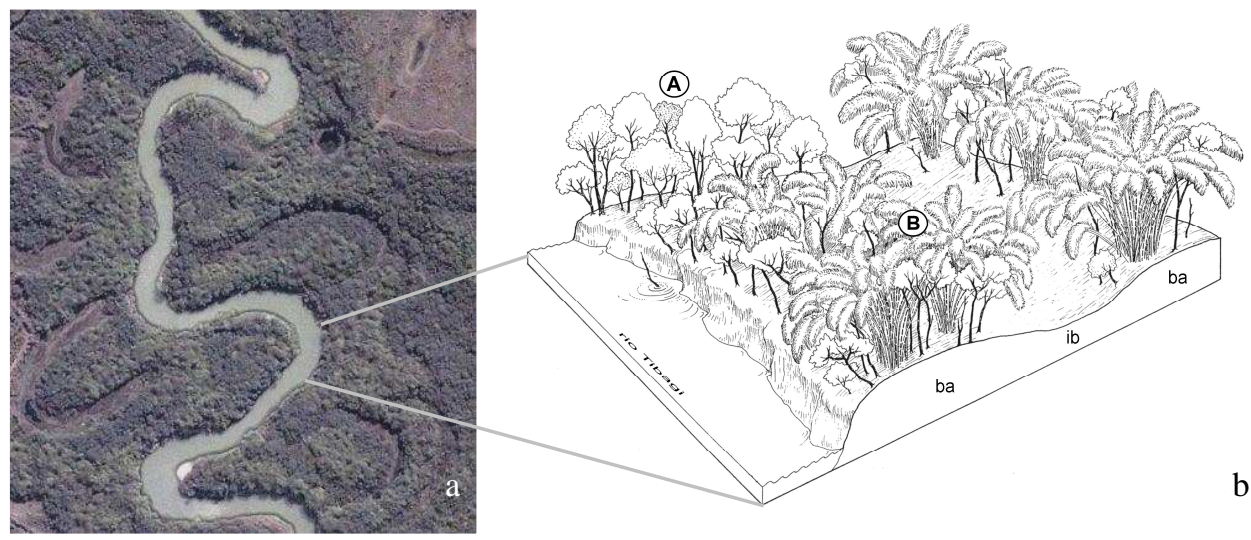

Figura 2. a: Áreas de Preservação Permanente às margens do rio Tibagi com presença de G. paraguayana (tons mais claros na vegetação); b: Floresta Ombrófila Mista Aluvial em superfície de degradação do rio Tibagi, em Ponta Grossa-PR. A e B: vegetação sem e com a presença do bambu, respectivamente; ba: barra; ib: interbarra. (Ilustração: Nelson Cosmo)

Figure 2. a: Permanent preservation areas on Tibagi's sides with presence of G. paraguayana (lighter vegetation); b: Subtropical Ombrophilous Alluvial Forest on degradation surface of Tibagi river, in Ponta Grossa-PR. A and B: vegetation without and with the presence of bamboo, respectively; ba: bar; ib: between bars. (Illustration: Nelson Cosmo)

O clima, segundo a classificação de Köppen, é do tipo $\mathrm{C} f b$, subtropical úmido mesotérmico, com temperatura média anual de $18-19{ }^{\circ} \mathrm{C}$, com médias mínima de $13,0{ }^{\circ} \mathrm{C}$ e máxima de $24,0{ }^{\circ} \mathrm{C}$. Na maior parte da área, os índices pluviométricos situam-se entre 1.400 e $1.600 \mathrm{~mm}$ anuais (MAACK, 1981; INSTITUTO AGRONÔMICO DO PARANÁ (IAPAR), 1994; CRUZ, 2007). Os registros de temperatura média e precipitação no período de acompanhamento da deposição e decomposição da serapilheira, para a região onde está inserida a área em estudo, estão na tabela 1. 
Tabela 1. Temperatura média e precipitação na região durante o período de estudo.

Table 1. Average temperature and precipitation in the region during the focused period.

\begin{tabular}{lcccccccccccc}
\hline & Dez/06 & Jan/07 & Fev/07 & Mar/07 & Abr/07 & Mai/07 & Jun/07 & Jul/07 & Ago/07 & Set/07 & Out/07 & Nov/07 \\
\hline $\begin{array}{l}\text { Temperatura } \\
\text { média }\left({ }^{\circ} \mathrm{C}\right)\end{array}$ & 22,1 & 22,1 & 22,1 & 22,5 & 20,2 & 15,5 & 15,8 & 13,6 & 16,2 & 19,4 & 20,1 & 19,9 \\
\hline $\begin{array}{l}\text { Precipitação } \\
(\mathrm{mm})\end{array}$ & 91,6 & 158,2 & 168,0 & 82,4 & 45,6 & 134,6 & 4,8 & 141,0 & 19,2 & 27,2 & 39,0 & 155,2 \\
\hline & Dez/07 & $\mathbf{J a n} / \mathbf{0 8}$ & $\mathbf{F e v / 0 8}$ & $\mathbf{M a r} / \mathbf{0 8}$ & $\mathbf{A b r} / \mathbf{0 8}$ & $\mathbf{M a i} / \mathbf{0 8}$ & $\mathbf{J u n} / \mathbf{0 8}$ & $\mathbf{J u l} / \mathbf{0 8}$ & $\mathbf{A g o / 0 8}$ & Set/08 & Out/08 & Nov/08 \\
\hline $\begin{array}{l}\text { Temperatura } \\
\text { média }\left({ }^{\circ} \mathrm{C}\right)\end{array}$ & 21,3 & 20,5 & 21,1 & 20,3 & 18,3 & 15,2 & 13,8 & 15,3 & 16,1 & 16,3 & 20,0 & 20,8 \\
\hline $\begin{array}{l}\text { Precipitação } \\
(\mathrm{mm})\end{array}$ & 215,0 & 124,8 & 120,0 & 125,0 & 198,8 & 77,4 & 122,6 & 55,6 & 144,4 & 45,2 & 133,9 & 90,3 \\
\hline
\end{tabular}

Fonte: SIMEPAR, estação 25135001, Ponta Grossa-PR (dados não publicados).

\section{Metodologia}

Caracterização química da espécie

Para a caracterização química, foram coletadas e secas em estufa de ventilação forçada a $60^{\circ} \pm 2{ }^{\circ} \mathrm{C}$ partes vivas de G. paraguayana: rizomas, colmos, galhos (ramos secundários), brotos, folhas da ramagem (lâminas e bainhas verdes, fotossintetizantes) e caulinares, raízes de barra e interbarra; e serapilheira produzida pela espécie. Cada uma das frações foi homogeneizada e reduzida a serragem em moinho do tipo Willey, no Laboratório de Química da Madeira/UFPR.

Amostras de trabalho foram enviadas ao Laboratório de Biogeoquímica e Nutrição de Plantas/UFPR para análise dos macronutrientes nitrogênio $(\mathrm{N})$, fósforo $(\mathrm{P})$, potássio $(\mathrm{K})$, cálcio $(\mathrm{Ca})$ e magnésio (Mg) e de carbono (C), de acordo com as normas descritas por Martins e Reissmann (2007).

Os teores de lignina, extrativos em etanol-tolueno e totais (normas Tappi) foram determinados no Laboratório de Química da Madeira. Pela diferença dos valores de extrativos totais, lignina e cinzas foram obtidos os valores de holocelulose (normas Tappi).

No Laboratório de Energia de Biomassa/UFPR, foram obtidos os valores para cinzas, voláteis, poder calorífico e carbono fixo das frações. As análises foram feitas segundo as normas da ABNT: umidade, NBR 7993; materiais voláteis, carbono fixo e cinzas, NBR 8112; poder calorífico (superior e inferior), NBR 8633.

Produção de serapilheira

A produção anual de serapilheira (Figura 3b) foi obtida por amostragem, com a instalação de 36 coletores distribuídos equitativamente ao longo da área em estudo (barra e interbarra). Os coletores continham sacos cônicos confeccionados em malha de nylon com $3 \mathrm{~mm}$ de abertura e armações de ferro com $50 \mathrm{~cm}\left(0,19635 \mathrm{~m}^{2}\right.$ de área) de diâmetro e $80 \mathrm{~cm}$ de altura (Figura 3c).

As coletas foram feitas mensalmente durante um ano. O material obtido foi separado em frações - folhas (outras espécies), folha caulinar, lâminas e bainhas foliares de G. paraguayana e miscelânea - e seco em estufa de ventilação forçada a $60^{\circ} \pm 2{ }^{\circ} \mathrm{C}$. As frações foram pesadas e os valores obtidos lançados em planilha Excel para obtenção de gráficos de deposição e sua extrapolação para hectare.

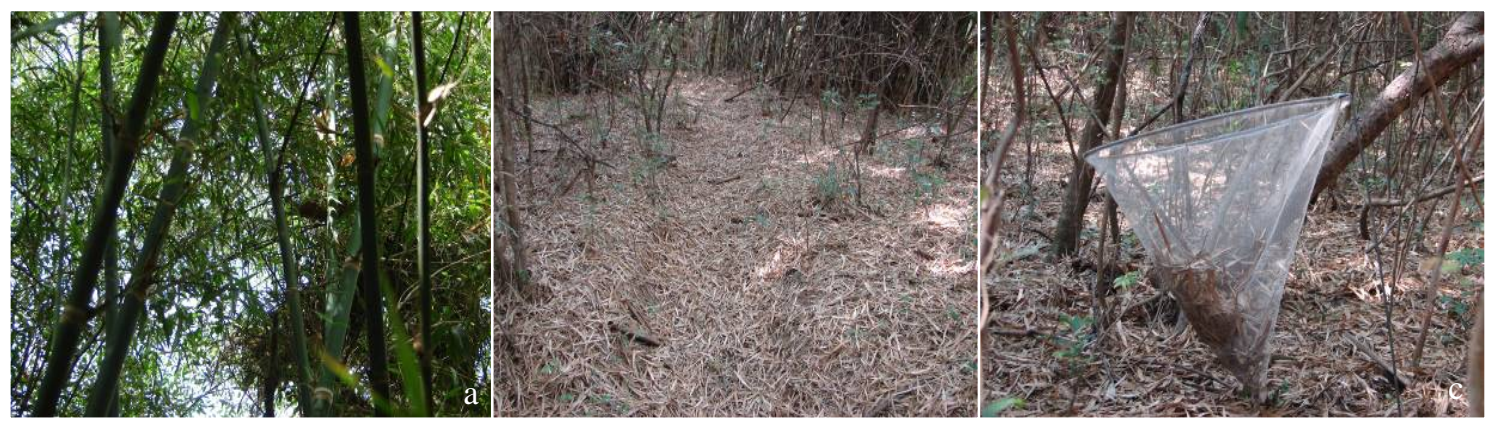

Figura 3. a: Dominância de G. paraguayana; b: deposição de serapilheira; c: coletor.

Figure 3. a: Dominance of G. paraguayana; b: litter fall; c: collector. 
Decomposição da serapilheira

Para o estudo de decomposição e análises químicas da serapilheira produzida por $G$. paraguayana, foram coletadas folhas da ramagem com até um mês de deposição (outubro/novembro de 2007). Como geralmente a lâmina se desprende naturalmente da bainha foliar e como suas consistências são muito diferentes - o que pode repercutir na velocidade de decomposição -, essas frações foram consideradas separadamente. Uma vez que a fragmentação faz parte do processo de decomposição, optouse por se trabalhar com lâminas indenes (com 100 a $80 \%$ de área foliar). Lâminas e bainhas foram secas em estufa de ventilação forçada a $60^{\circ} \pm 2{ }^{\circ} \mathrm{C}$ até peso constante.

A avaliação da decomposição foi feita pelo método direto. Foram utilizados 72 sacos de decomposição medindo $15 \times 20 \mathrm{~cm}$, confeccionados em nylon, com malha de $2 \mathrm{~mm}$ de diâmetro, 48 deles contendo $5 \mathrm{~g}$ cada de lâminas foliares secas, e 24 com $5 \mathrm{~g}$ cada de bainhas foliares secas.

Para testar duas variáveis no mesmo ambiente (lâminas e bainhas foliares em barra) e dois ambientes para uma mesma variável (lâmina foliar em barra e interbarra), o material foi levado a campo em 4/12/2007 e disposto em quatro parcelas, duas em barra (lâminas e bainhas foliares) e duas em interbarras (apenas lâminas). Para a instalação, foi removida a camada superficial de serapilheira e, para evitar a remoção pelos pulsos de inundação, as amostras foram fixadas no chão, uma ao lado da outra, com fio de nylon e piquete metálico. Os sacos foram cobertos com uma camada fina de lâminas foliares recém-caídas. O local foi sinalizado com fitilho colorido preso ao piquete metálico.

A cada dois meses, 12 sacos eram coletados para análise, 8 de lâminas (barra e interbarras) e 4 de bainhas (apenas na barra). As amostras recolhidas foram submetidas a triagem, retirando-se raízes e partículas de solo, acondicionadas em sacos de papel identificados, secas em estufa com ventilação forçada a $60^{\circ} \pm 2{ }^{\circ} \mathrm{C} \mathrm{e}$ pesadas, sendo os dados lançados no software Excel para obtenção da curva de decomposição. A última coleta foi feita em 11/12/2008.

O acompanhamento das amostras (pesagem) gerou os valores usados na determinação da velocidade de decomposição pela redução de biomassa em relação ao peso inicial.

Calculou-se, então, a taxa de decomposição (k) da fração foliar (lâminas e bainhas separadamente) de G. paraguayana, utilizando-se a fórmula proposta por Jenny et al. (1949) e Olson (1963): $\mathrm{k}=-\ln [1$ - (quantidade de biomassa perdida no tempo/biomassa inicial)]. A partir desse coeficiente, estimou-se o tempo médio para a decomposição de $50 \%$ do material pela fórmula de Olson (1963): $\mathrm{T}_{50 \%}=-\ln 0,5 / \mathrm{k}$; e os períodos de decomposição de $95 \%$ e de $99 \%$ do material, pelas fórmulas: $\mathrm{T}_{95 \%}=3,0 / \mathrm{k} \mathrm{e} \mathrm{T}_{99 \%}=5,0 / \mathrm{k}$.

Raízes

Para o mapeamento das raízes, foram coletadas amostras distribuídas ao longo de linhas ortogonais, em profundidades variadas, de duas touceiras. As coletas foram feitas por meio de um amostrador de aço inoxidável com diâmetro médio de $11 \mathrm{~cm}$ e profundidade de $10 \mathrm{~cm}\left(975,55 \mathrm{~cm}^{3}\right)$. Nas linhas perpendiculares (cruzando barra e interbarra), foram obtidas amostras a 0, 2, 4, 6, 8 e $10 \mathrm{~m}$, coletando-se material nas profundidades de 10,20 e $30 \mathrm{~cm}$ nos pontos a 0 e $10 \mathrm{~m}$. Nas linhas ao longo da barra, foram amostrados os pontos $0,2 \mathrm{e} 4 \mathrm{~m}$. Nos pontos 0 e $4 \mathrm{~m}$, coletou-se material nas profundidades 10,20 e $30 \mathrm{~cm}$. Em ambas as linhas, nos demais pontos, as amostras foram retiradas com $10 \mathrm{~cm} \mathrm{de}$ profundidade.

Cada amostra foi peneirada para a retirada do excesso de terra, embalada em sacos plásticos, identificada e levada para processamento no Laboratório de Ecologia Florestal - LECOF/UFPR. As raízes de $G$. paraguayana foram lavadas em água corrente para a retirada da terra e de outros contaminantes (inclusive raízes de outras espécies), secas em estufa de ventilação forçada a $60^{\circ} \pm 2{ }^{\circ} \mathrm{C}$ e pesadas. Os dados foram lançados no software Excel para obtenção da curva de distribuição das raízes e do coeficiente de correlação $\mathrm{R}^{2}$.

\section{RESULTADOS E DISCUSSÃO}

A presença de G. paraguayana é expressiva nas barras, onde se impõe sobre a floresta formada principalmente por Sebastiania commersoniana. Nas interbarras, a saturação hídrica do solo dificulta o estabelecimento de qualquer vegetação. 


\section{Caracterização química da espécie}

O investimento da planta nos órgãos em crescimento é indicado pelos altos teores de nutrientes alocados nesses tecidos. Em relação ao colmo adulto, o broto de G. paraguayana tem, como esperado, maiores teores de N, P, K, Ca e Mg. Os altos teores de nutrientes no rizoma explicam sua função de órgão de reserva e provedor da brotação (Tabela 2).

Tabela 2. Concentração dos macronutrientes $\mathrm{N}, \mathrm{P}, \mathrm{K}, \mathrm{Ca}$ e $\mathrm{Mg}$, de $\mathrm{C}$ e a relação $\mathrm{C} / \mathrm{N}$ nas porções vivas do bambu G. paraguayana.

Table 2. Concentration of macronutrients $\mathrm{N}, \mathrm{P}, \mathrm{K}, \mathrm{Ca}$ and $\mathrm{Mg}, \mathrm{C}$ and $\mathrm{C} / \mathrm{N}$ ratio in the bamboo's, $G$. paraguayana, constituent parts.

\begin{tabular}{lccccccc}
\hline Fração & $\mathbf{N}(\mathbf{g} / \mathbf{k g})$ & $\mathbf{P}(\mathbf{g} / \mathbf{k g})$ & $\mathbf{K}(\mathbf{g} / \mathbf{k g})$ & $\mathbf{C a}(\mathbf{g} / \mathbf{k g})$ & $\mathbf{M g}(\mathbf{g} / \mathbf{k g})$ & $\mathbf{C}(\mathbf{\%})$ & $\mathbf{C} / \mathbf{N}$ \\
\hline Broto & 17,33 & 1,38 & 18,59 & 1,10 & 1,29 & 42,31 & 24,41 \\
Colmo & 8,74 & 0,00 & 6,97 & 0,94 & 0,32 & 45,22 & 51,72 \\
Lâmina foliar verde & 28,50 & 1,34 & 15,00 & 4,57 & 1,28 & 44,44 & 15,59 \\
Bainha foliar verde & 7,39 & 0,02 & 6,61 & 1,22 & 1,06 & 39,19 & 53,04 \\
Folha caulinar & 8,88 & 0,00 & 6,69 & 1,28 & 0,18 & 44,66 & 50,28 \\
Galho & 8,20 & 0,10 & 7,52 & 0,58 & 0,48 & 44,60 & 54,40 \\
Raiz barra & 8,78 & 0,00 & 3,29 & 0,95 & 1,02 & 41,25 & 46,99 \\
Raiz interbarra & 10,43 & 0,00 & 2,50 & 0,84 & 0,74 & 41,71 & 39,67 \\
Rizoma & 21,05 & 0,76 & 19,10 & 0,79 & 1,00 & 44,35 & 21,07 \\
\hline
\end{tabular}

Ambos com função de sustentação, colmos e galhos têm lignificação de 22,39\% e 23,50\%, respectivamente. Nos brotos, o teor de lignina é de apenas 10\% (Tabela 2). A sustentação da brotação é feita mecanicamente por pressão de turgor nas células. A lignina é depositada ao longo do tempo, com o amadurecimento dos colmos, atingindo seu máximo na fase senil (JUDZIEWICZ et al., 1999). Os teores de extrativos totais (amido, ceras, taninos, resinas, óleos...) são mais expressivos nas lâminas das folhas ainda verdes, brotos e rizomas, evidenciando o esforço da planta na proteção de seus órgãos de reserva e de produção (Tabela 3).

Tabela 3. Composição orgânica por fração de G. paraguayana.

Table 3. Organic composition in fractions of G. paraguayana.

\begin{tabular}{|c|c|c|c|c|c|}
\hline Fração & $\begin{array}{c}\text { Extrativos em etanol- } \\
\text { tolueno }(\%)\end{array}$ & $\begin{array}{c}\text { Extrativos totais } \\
(\%)\end{array}$ & $\begin{array}{c}\text { Lignina } \\
(\%)\end{array}$ & $\begin{array}{c}\text { Cinzas } \\
(\%)\end{array}$ & $\begin{array}{c}\text { Holocelulose } \\
(\%)\end{array}$ \\
\hline \multicolumn{6}{|c|}{ Porção viva } \\
\hline Broto & 16,60 & 28,04 & 9,99 & 5,23 & 56,73 \\
\hline Colmo & 7,29 & 11,86 & 22,39 & 2,61 & 63,15 \\
\hline Lâmina foliar verde & 16,53 & 25,57 & 19,94 & 7,09 & 47,40 \\
\hline Bainha foliar verde & 8,31 & 17,10 & 22,46 & 5,73 & 54,71 \\
\hline Folha caulinar & 3,53 & 10,37 & 21,50 & 3,32 & 64,81 \\
\hline Galho & 7,60 & 10,71 & 23,50 & 2,66 & 63,13 \\
\hline Raiz barra & 3,10 & 6,95 & 36,38 & 11,30 & 45,37 \\
\hline Raiz interbarra & 3,27 & 8,01 & 33,23 & 10,44 & 48,32 \\
\hline Rizoma & 11,12 & 20,10 & 23,14 & 5,00 & 51,77 \\
\hline \multicolumn{6}{|c|}{ Serapilheira } \\
\hline Lâmina foliar & 7,66 & 15,46 & 35,53 & 21,96 & 27,05 \\
\hline Bainha foliar & 3,57 & 9,82 & 28,01 & 9,25 & 52,92 \\
\hline
\end{tabular}

Além de facilmente translocados, carboidratos e aminoácidos entram rapidamente em decomposição quando remanescentes. Por isso, a proporção de lignina e cinzas é muito superior nas folhas (lâminas e bainhas) componentes da serapilheira do que nas folhas fotossintetizantes em atividade (verdes) (Tabela 3). Há, ainda, a capacidade de as plantas depositarem nos tecidos em decadência os produtos residuais. Desse modo, a diferença entre os componentes funcionais e os senescentes é bastante expressiva (MASON, 1980) (Tabelas 2, 3 e 8). 
O alto percentual de cinzas nas raízes, tanto em condição de barra quanto de interbarra (inundações frequentes), está em consonância com seu papel na absorção de nutrientes minerais.

Os teores de extrativos totais, lignina e holocelulose encontrados para o colmo estão dentro da média esperada (BRITO et al., 1987) para os bambus e particularmente próximos dos da espécie Dendrocalamus giganteus (Tabela 4), independentemente do fato de G. paraguayana ser um bambu maciço, com predominância de tecido parenquimático na porção central.

Tabela 4. Comparação dos teores de extrativos totais, de lignina e holocelulose de G. paraguayana, Dendrocalamus giganteus e média para bambus.

Table 4. Comparison extractive levels of lignin and holocellulose of G. paraguayana, Dendrocalamus giganteus and the average of bamboos.

\begin{tabular}{lccc}
\hline & Extrativos totais $(\boldsymbol{\%})$ & Lignina $(\%)$ & Holocelulose $(\%)$ \\
\hline G. paraguayana & $11,9^{*}$ & $22,4^{*}$ & $63,1^{*}$ \\
D. giganteus $* *$ & $12,9^{* *}$ & $23,4^{* *}$ & $63,7^{* *}$ \\
Média para bambus** & $15,2^{* *}$ & $20,1^{* *}$ & $64,6^{* *}$ \\
\hline
\end{tabular}

* Os valores para G. paraguayana não fecham $100 \%$ porque também foram determinadas as cinzas (ausentes para os outros componentes desta tabela). **Fonte: Brito et al., 1987.

\section{Poder calorífico e teor de carbono fixo}

Para determinar o potencial de uso desse bambu, foram analisados, no Laboratório de Energia da Biomassa/UFPR, o poder calorífico e o teor de carbono fixo. A parte aérea de G. paraguayana (colmo, galhos e folhas fotossintetizantes e caulinares) apresentou, em média, poder calorífico acima de $4.000 \mathrm{Kcal} / \mathrm{kg}$, o que recomenda sua utilização na geração direta de energia (queima) (Tabela 5). Sua utilização em fornalhas, no entanto, está na dependência da determinação do teor de silício, já que a presença desse elemento pode inviabilizar a operação.

Tabela 5. Poder calorífico das porções de G. paraguayana.

Table 5. Calorific value of portions of G. paraguayana.

\begin{tabular}{lc}
\hline Amostra & Poder calorífico (Kcal/kg) \\
\hline Broto & \\
Colmo & Porção viva \\
Lâmina foliar verde & 4201,40 \\
Bainha foliar verde & 4022,88 \\
Folha caulinar & 4524,94 \\
Galho & 3845,14 \\
Raiz barra & 4030,62 \\
Raiz interbarra & 4235,55 \\
Rizoma & 3734,27 \\
& \\
\hline Lâmina foliar & 3986,24 \\
Bainha foliar & 4299,61 \\
\hline
\end{tabular}

O colmo de G. paraguayana apresentou poder calorífico de 4.022,88 Kcal $/ \mathrm{kg}, 75,90 \%$ de materiais voláteis, $21,32 \%$ de carbono fixo e $2,77 \%$ de cinzas (material inorgânico). Para as madeiras, os teores de voláteis - parte da biomassa que queima na forma gasosa (labaredas) - estão entre 78 e $82 \%$, e o carbono fixo - combustão em forma de brasa -, entre 16 e $28 \%$. O teor de carbono fixo para toda a parte aérea (colmo, folhas fotossintetizantes e galhos) ficou acima de $21 \%$ (Tabela 6).

\section{Deposição e ciclagem de serapilheira}

Como a ação desse bambu sobre a vegetação estabelecida é intensa - diminuição de sub-bosque, epifitismo e regeneração (GALVÃO et al., prelo) -, há pouca contribuição de outras espécies na formação de serapilheira. Assim, a deposição G. paraguayana, formada predominantemente por folhas caulinares e dos ramos, corresponde, nas barras, a 95,90\% da produção total nesse ambiente. Apenas a 
fração folha fotossintetizante (lâmina + bainha) respondeu por 93,83\% da deposição. No período de acompanhamento, dezembro/2006 a novembro/2007, foram depositados, no total, $7.500 \mathrm{~kg} / \mathrm{ha}$ em ambiente de barra. O maior aporte ocorreu nos meses de outubro e novembro, com mais de $1.000 \mathrm{~kg} / \mathrm{ha} / \mathrm{mês}$, e o menor, em janeiro e fevereiro, com, em média, $370 \mathrm{~kg} / \mathrm{ha} / \mathrm{mês}$ (Figura 4).

Tabela 6. Teores de voláteis, carbono fixo e cinzas de G. paraguayana.

Table 6. Volatile content, fixed carbon and ashes of G. paraguayana.

\begin{tabular}{lccc}
\hline Amostra & Voláteis (\%) & Carbono fixo (\%) & Cinzas (\%) \\
\hline Broto & Porção viva & \\
Colmo & 74,26 & 20,85 & 4,89 \\
Lâmina foliar verde & 75,90 & 21,32 & 2,77 \\
Bainha foliar verde & 71,31 & 21,60 & 7,09 \\
Folha caulinar & 72,78 & 21,77 & 5,44 \\
Galho & 77,16 & 19,52 & 3,32 \\
Raiz barra & 75,86 & 21,48 & 2,66 \\
Raiz interbarra & 69,49 & 19,21 & 11,30 \\
Rizoma & 69,10 & 20,46 & 10,44 \\
\hline \multicolumn{4}{c}{} \\
\hline Lâmina foliar & 72,33 & 22,67 & 5,00 \\
Bainha foliar & Serapilheira \\
\hline
\end{tabular}

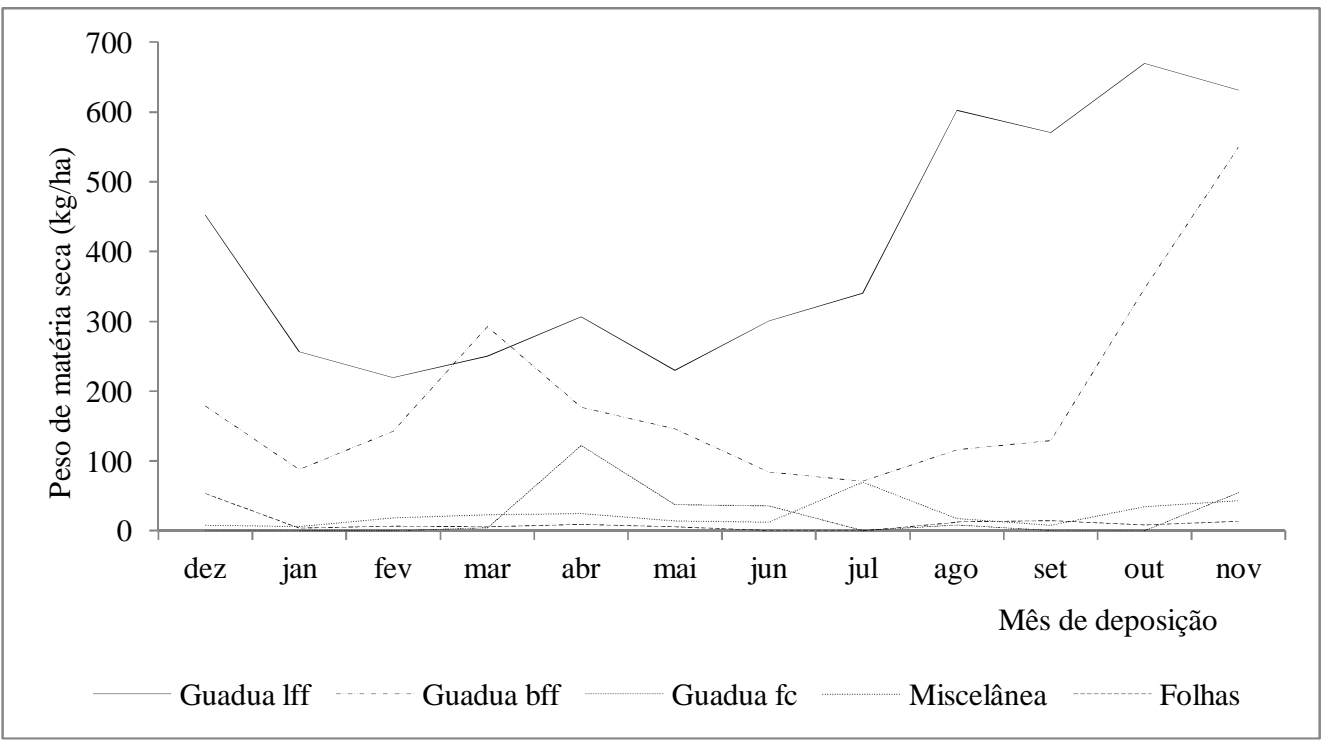

Figura 4. Deposição anual de serapilheira, em condição de barra, em FOMA sob influência de $G$. paraguayana. Guadua lff: lâmina de folhas fotossintetizantes (da ramagem); Guadua bff: bainha de folhas fotossintetizantes; Guadua fc: folhas caulinares; folhas: folhas de outras espécies; miscelânea.

Figure 4. Annual litter fall, in bar conditions, in Subtropical Ombrophilous Alluvial Forest under influence of $G$. paraguayana. Guadua lff: photosynthetic blades leaves; Guadua bff: photosynthetic sheaths leaves (and) photosynthetic leaves; Guadua fc: culm leaves; leaves: other species leaves; miscellany.

O valor total obtido está dentro do esperado para florestas tropicais, que é de 5.000 a $15.000 \mathrm{~kg} / \mathrm{ha} /$ ano (BRAY; GORHAM, 1964). Para a Floresta Ombrófila Mista (FOM), já foram registrados valores de $7.700 \mathrm{~kg} / \mathrm{ha} / \mathrm{ano}$ em São João do Triunfo/PR (FIGUEIREDO FILHO et al., 2003), 
e $8.300 \mathrm{~kg} / \mathrm{ha} / \mathrm{ano}$ em Santa Catarina (FLOSS et al., 1999). Para a FOMA nas margens do rio Barigui, Araucária/PR, Sousa (2003) encontrou $9.440 \mathrm{~kg} / \mathrm{ha} / \mathrm{ano}$.

A presença do bambu provocou mudanças no período de deposição. Na FOMA, onde predomina o branquilho, a maior produção de serapilheira ocorre no inverno. Onde G. paraguayana está presente, a maior deposição se dá na primavera.

O estudo de ciclagem revelou meia vida superior a 260 dias para as lâminas e 360 dias para as bainhas foliares (Tabela 7). Em condições de barra, lâminas e bainhas apresentam velocidades diferentes de ciclagem devido à estrutura/formato (facilidade de ataque por organismos decompositores), aos teores de nutrientes lixiviáveis ou palatáveis (extrativos totais: 15,5\% em lâminas e 9,8\% nas bainhas, Tabela 4) e à relação $\mathrm{C} / \mathrm{N}$ (carbono/nitrogênio, Tabela 8). A diferença nos ritmos de ciclagem das lâminas (barra x interbarra) se deve às condições ambientais. As barras são regiões alçadas, livres de inundação frequente. Nas interbarras, a umidade está presente durante o ano todo.

Tabela 7. Estimativa do tempo médio para decomposição de 50, 95 e $99 \%$ da biomassa foliar de $G$. paraguayana.

Table 7. Estimated average time for decomposition of 50, 95, and 99\% of G. paraguayana's leaves biomass.

\begin{tabular}{lcccccc}
\hline \multicolumn{1}{c}{ Fração } & $\mathbf{T}_{\mathbf{5 0 \%}}$ & $\begin{array}{c}\mathbf{N}^{\mathbf{0}} \text { de dias para } \\
\mathbf{5 0 \%}\end{array}$ & $\mathbf{T}_{\mathbf{9 5 \%}}$ & $\mathbf{N}^{\mathbf{0}}$ de dias para & $\mathbf{T}_{\mathbf{9 5 \%}}$ & $\begin{array}{c}\mathbf{N}^{\mathbf{0}} \text { de dias para } \\
\mathbf{9 9 \%}\end{array}$ \\
\hline Lâmina & 0,72 & 263 & 3,13 & 1.141 & 5,21 & 1.901 \\
Bainha & 0,99 & 361 & 4,29 & 1.564 & 7,14 & 2.607 \\
\hline
\end{tabular}

Tabela 8. Concentração de nutrientes devolvidos para o ambiente pela deposição de folhas de $G$. paraguayana, em condição de barra.

Table 8. Concentration of nutrients returned to environment by deposition of G. paraguayana leaves under bar's condition.

\begin{tabular}{lccccccc}
\hline Serapilheira & $\mathbf{N}$ & $\mathbf{P}$ & $\mathbf{K}$ & $\mathbf{C a}$ & $\mathbf{M g}$ & $\mathbf{C}$ & C/N \\
\hline & & \multicolumn{7}{c}{$(\mathrm{g} / \mathrm{kg})$} & & & & \\
\hline Lâmina foliar & 14,24 & 0,06 & 1,89 & 9,01 & 1,69 & 363,9 & 25,56 \\
Bainha foliar & 8,64 & 0,00 & 2,39 & 1,33 & 1,90 & 427,2 & 49,44 \\
Folha (lâmina 2/3 + bainha & 12,37 & 0,04 & 2,06 & 6,45 & 1,76 & 385,0 & 31,12 \\
1/3) & \multicolumn{7}{c}{$(\mathrm{kg} / \mathrm{ha})$} \\
\hline & 89,60 & 0,29 & 14,92 & 46,72 & 12,75 & $2.788,81$ & 31,12 \\
\hline Folha
\end{tabular}

Considerando-se os valores encontrados para carbono orgânico nessas frações, a relação $\mathrm{C} / \mathrm{N}$ para as lâminas é de 25,56 e, para as bainhas, 49,44 (Tabela 8). Quanto mais baixo o valor dessa relação, mais favorável à ciclagem. Valores próximos a 25 significam que a matéria orgânica fornece proporções de $\mathrm{C}$ e $\mathrm{N}$ adequadas ao metabolismo dos organismos decompositores (JORDAN, 1985). Para as folhas de branquilho, espécie predominante em ambientes preservados da FOMA, Sousa (2003) encontrou 24,26, e para uma composição de folhas das espécies típicas dessa formação, 21,78.

A presença dominante desse bambu diminuiu a quantidade de nutrientes devolvidos ao meio pela decomposição da fração folhas fotossintetizantes da serapilheira. No período analisado, lâminas e bainhas retornaram ao ambiente $164,27 \mathrm{~kg} / \mathrm{ha}$ dos macronutrientes $\mathrm{N}, \mathrm{P}, \mathrm{K}, \mathrm{Mg}$ e Ca. O nitrogênio é o elemento mais abundante, com 54,54\% do total de nutrientes transferidos (Tabela 8). As análises revelaram também a dimensão da translocação de nutrientes. As lâminas das folhas colhidas verdes apresentam maiores teores de N, P e K (Tabela 2), em comparação com as lâminas depositadas na serapilheira (Tabela 8). O valor de Ca é maior nestas últimas, conforme Malavolta (1980), indicando a imobilidade desse elemento.

Em estudo realizado em FOMA inalterada no município de Araucária/PR, Sousa (2003) encontrou, para a fração folha (composição de espécies), os valores: 20,63 g/kg de N; 1,05 g/kg de P; $5,17 \mathrm{~g} / \mathrm{kg}$ de $\mathrm{K} ; 14,18 \mathrm{~g} / \mathrm{kg}$ de $\mathrm{Ca} ;$ e 2,85 g/kg de Mg. Além de esses serem valores mais elevados que os 
de G. paraguayana, há, na floresta preservada, a deposição de flores e frutos, o que garante uma alocação expressiva de elementos minerais.

Os valores obtidos para as concentrações de macronutrientes na fração folha de Guadua mantêm a tendência registrada para os ecossistemas florestais (HAAG et al.,1985): $\mathrm{N}>\mathrm{Ca}>\mathrm{K}>\mathrm{Mg}>\mathrm{P}$ (Tabela 8).

Com base na concentração de carbono da folha $-363,9 \mathrm{~g} / \mathrm{kg}$ para as lâminas e 427,2 g/kg para as bainhas-, foi possível estimar um fluxo de carbono orgânico da vegetação para o solo da ordem de $2.800 \mathrm{~kg} / \mathrm{ha} / \mathrm{ano}$, abaixo do encontrado na literatura. Sousa (2003) estabeleceu para FOMA $3.980 \mathrm{~kg} / \mathrm{ha} / \mathrm{ano}$, e Figueiredo Filho et al. (2003), para a FOM Montana, $3.000 \mathrm{~kg} / \mathrm{ha} / \mathrm{ano}$.

$\mathrm{O}$ menor teor de nutrientes da serapilheira gerada por G. paraguayana pode explicar, nesse ambiente, o retardamento na decomposição.

A partir dos valores obtidos para a biomassa foliar remanescente nas bolsas, foi possível ajustar equações de decomposição da fração lâmina foliar em barra e interbarra e frações lâmina e bainha foliar em condição de barra. A equação de decomposição encontrada para as lâminas foliares de $G$. paraguayana foi: $\mathrm{Y}=0,0003 \mathrm{x}^{2}-0,2568 \mathrm{x}+97,13$, com coeficiente de correlação $\left(\mathrm{R}^{2}\right)$ de 0,9132 . Na comparação entre os constituintes da folha fotossintetizante (lâmina e bainha), em ambiente de barra, a equação ajustada foi: $Y=0,0001 x^{2}-0,1806 x+97,101$, com coeficiente de correlação $\left(R^{2}\right)$ de 0,9236 . Para ambas, Y é a biomassa remanescente calculada em função do número de dias a partir da instalação do experimento no campo. O padrão das curvas revela perda inicial mais acentuada (verão - temperatura e umidade - e substâncias facilmente liberadas), com gradual estabilização ao longo do período de acompanhamento.

Com os valores de biomassa, calculou-se ainda o coeficiente de decomposição "k" para lâmina e bainha. A seguir, estimou-se o tempo médio para decomposição de 50, 95 e $99 \%$ das frações em estudo (Tabela 7).

Os coeficientes "k" para $\mathrm{T}_{50 \%}$ encontrados para lâmina e bainha são, respectivamente, 0,96 e 0,70 , indicando baixa taxa de decomposição, com consequente acumulação de matéria orgânica. Segundo Haag et al. (1985), o coeficiente "k" para decomposição de serapilheira varia, em florestas tropicais, de 1,1 a 3,8 , enquanto que nas florestas temperadas esse coeficiente fica entre 0,4 e 1,4 , indicando, no primeiro caso, curto e, no segundo, longo período de permanência da matéria orgânica no solo.

\section{Raízes}

Como monocotiledônea, G. paraguayana tem raízes fasciculadas extensamente ramificadas, formando um complexo sistema radicular. Nele, não é possível distinguir nenhum eixo principal e o diâmetro das raízes varia pouco. As mais grossas têm, em média, 4 mm de diâmetro. As mais finas coletadas apresentam cerca de $1 \mathrm{~mm}$ de diâmetro.

Tudo indica que a competitividade desse bambu é ampliada pela habilidade na obtenção de água e nutrientes assegurada pela extensa malha de raízes finas superficiais. Além de se estenderem, nas touceiras avaliadas, por um raio de mais de $10 \mathrm{~m}$ da base da reboleira (área proporcional à projeção da porção apical dos colmos), $85 \%$ delas estão a até $20 \mathrm{~cm}$ de profundidade, o que permite à planta a absorção quase que exclusiva dos nutrientes liberados, numa ciclagem direta planta a planta (Figura 5).
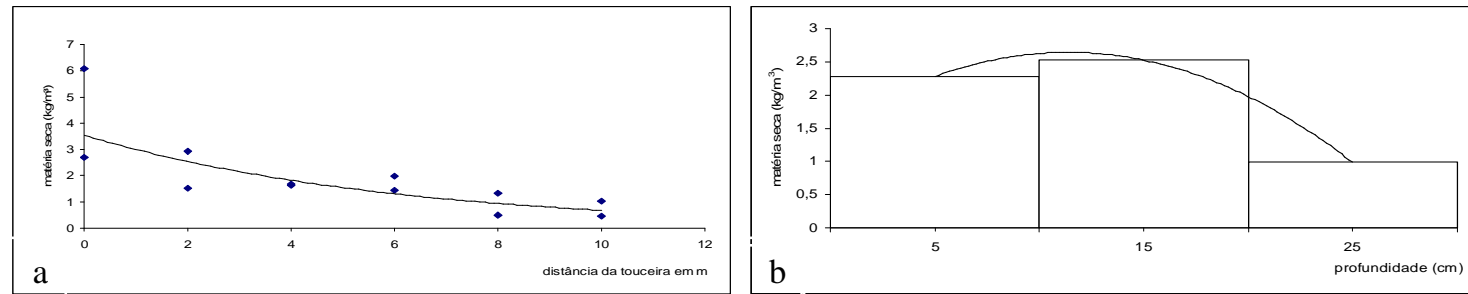

Figura 5. a) Distribuição das raízes $\left(\mathrm{kg} / \mathrm{m}^{3}\right)$ de G. paraguayana em até $10 \mathrm{~cm}$ de profundidade, a partir da base da reboleira; b) Distribuição das raízes $\left(\mathrm{kg} / \mathrm{m}^{3}\right)$ de G. paraguayana em três níveis de profundidade: até $10 \mathrm{~cm}$, de 10 a $20 \mathrm{~cm}$ e de 20 a $30 \mathrm{~cm}$.

Figure 5. a) Roots distribution $\left(\mathrm{kg} / \mathrm{m}^{3}\right)$ of G. paraguayana from the surface until $10 \mathrm{~cm}$ deep, starting at the base of the bamboo cluster; b) Distribution $\left(\mathrm{kg} / \mathrm{m}^{3}\right)$ of $\mathrm{G}$. paraguayana roots in three levels: until $10 \mathrm{~cm}$ deep, from 10 to $20 \mathrm{~cm}$ deep, and from 20 to $30 \mathrm{~cm}$ deep. 
O sistema radicular de G. paraguayana se estende inclusive para as interbarras, regiões onde as inundações frequentes dificultam o estabelecimento desta e de outras espécies. Na interbarra, as raízes podem absorver, além de água, os nutrientes liberados pela ciclagem de serapilheira aí depositada pela projeção das copas das árvores da FOMA e da porção arqueada do ápice dos colmos do próprio bambu.

Para a distribuição em distância das raízes de G. paraguayana, foi obtida, por regressão, a equação: $\mathrm{Y}=3,5434 \mathrm{e}^{-0,1658 \mathrm{x}}$, em que $\mathrm{Y}$ é a quantidade de raiz (peso seco) em $\mathrm{kg} / \mathrm{m}^{3} \mathrm{e} \mathrm{x}$, a distância da base da reboleira em metros. O R ${ }^{2}$ obtido foi de 0,6915 .

Para a determinação da distribuição em profundidade (valores médios), foi obtida a equação: $\mathrm{Y}=-0,8934 \mathrm{x}^{2}+2,9261 \mathrm{x}+0,2446$, em que $\mathrm{Y}$ é a quantidade de raiz (peso seco) em $\mathrm{kg} / \mathrm{m}^{3}$ e $\mathrm{x}$, a distância a partir da superfície do terreno em $\mathrm{cm}$.

\section{CONCLUSÕES}

- A deposição de serapilheira de G. paraguayana apresenta variação sazonal e o volume máximo é atingido em período diferente do estabelecido para a espécie predominante em fragmentos preservados da Floresta Ombrófila Mista Aluvial (FOMA), Sebastiania commersoniana, o branquilho.

- Sob influência desse bambu, o fluxo de nutrientes e de carbono orgânico para o ambiente é inferior ao determinado para a FOMA inalterada.

- O bambu não é a causa primária da degradação; é um complicador. A diminuição de nutrientes no ambiente, durante a ciclagem, pode ter consequências para a sustentabilidade do ecossistema, alterar sua resiliência e afetar o processo sucessional. No entanto, a dinâmica aberta característica dessa formação não permite determinar o alcance desse menor retorno de nutrientes ao meio. Essa planície aluvial, cercada por cultivos agrícolas, pode estar recebendo nutrientes provenientes das áreas adjacentes.

- As análises de carbono fixo e poder calorífico indicam bom potencial de uso da biomassa desse bambu para geração de energia. Para uso em caldeiras, no entanto, é necessário avaliar o teor de silício presente no material.

- A dinâmica da área, com deposição recente de sedimentos, também afeta o volume de raízes em profundidade. Para essa condição de terreno, o comum seria um volume maior na porção mais superficial (até $10 \mathrm{~cm}$ de profundidade). Os maiores valores obtidos, porém, foram entre 10 e $20 \mathrm{~cm}$.

- Para cumprir as finalidades de sua criação, o Refúgio da Vida Silvestre do Rio Tibagi deve estar em condições de preservar fauna e flora locais e desempenhar a função de corredor ecológico de vale. A presença não manejada de G. paraguayana compromete ambos os objetivos.

\section{AGRADECIMENTOS}

Ao Dr. Tarciso S. Filgueiras (Reserva Ecológica do IBGE), pelo complexo trabalho de identificação da espécie Guadua paraguayana Döll; ao Prof. Dr. Dimas Agostinho da Silva e equipe, Laboratório de Energia de Biomassa/PR; ao Prof. Dr. Humberto Klock e equipe, Laboratório de Química da Madeira/UFPR; ao Prof. Dr. Renato Marques e equipe, Laboratório de Biogeoquímica e Nutrição de Plantas/UFPR; ao Prof. Dr. Antônio Carlos Nogueira e equipe, Laboratório de Sementes/UFPR; e ao SIMEPAR, pelos dados gentilmente cedidos.

\section{REFERÊNCIAS}

BRAY, J. R.; GORHAM, E. Litter production in the forests of the world. In: CRAAG, J. B. Advances in ecological research, v. 2, p. $101-157,1964$.

BRITO, J. O.; TOMAZEllo FILHO; SAlGADO, A. L. B. Produção e caracterização do carvão vegetal de espécies e variedades de bambu, 1987. Disponível em http://www.ipef.br/publicacoes /scientia/nr36/cap02.pdf. Acesso em: 23/06/2008. 
CRUZ, G. C. F. Alguns aspectos do clima dos Campos Gerais. In: MELO, M. S.; MORO, R. S.; GUIMARÃeS, G. B. (Eds.). Patrimônio natural dos Campos Gerais do Paraná. Ponta Grossa: Editora da UEPG, p. 59 - 72, 2007.

DELITTI, W. B. C. Estudos de ciclagem de nutrientes: instrumentos para a análise funcional de ecossistemas terrestres. Oecologia Brasiliensis, v. 1, p. 469 - 486, 1995.

FIGUEIREDO FILHO, A.; MORAES, G. F.; SCHAAF, L. B.; FIGUEIREDO, D. J. de. Avaliação estacional da deposição de serapilheira em uma Floresta Ombrófila Mista localizada no sul do estado do Paraná. Ciência Florestal, Santa Maria-RS, v. 3, n. 1, p. 11 - 18, 2003.

FILGUEIRAS, T.; GONÇALVES, A. P. A checklist of the basal grasses and bamboos in Brazil (Poaceae). Bamboo Science and Culture: The Journal of the American Bamboo Society. v. 18, n. 1, p. 7-18, 2004. Disponível em: <www.americanbamboo.org/ABSJournalArchive/index.html>. Acesso em: $22 / 02 / 2008$.

FLOSS, P. A.; CADALTO, S. L.; BOHNER, J. A. M. Produção e decomposição de serapilheira na Floresta Ombrófila Mista da Reserva Florestal da EPAGRI/EMBRAPA de Caçador, SC. Revista Agropecuária Catarinense, Concórdia-SC, v. 12, n. 2, p. 19 - 22, 1999.

GALVÃO, F.; AUGUSTIN, C. R.; DOMANOWSKI, B. P.; KOZERA, C.; SAWCZUK; A. T.; CURCIO, G. R.; BONNET, A. Autoecologia de Guadua aff. paraguayana Döll (POACEAE). Pesquisa Florestal Brasileira/Brazilian Journal of Forestry Research. EMBRAPA, Colombo-PR, v. 58, p. 5 - 16, 2009.

GALVÃO, F.; RODERJAN, C. V.; POZZOBON, M.; AUGUSTIN, C. R.; CURCIO, G. R.; COSMO, N. L.; SANTOS, A. P. G. dos; DREZZA, T. R.; ANDRADE, B. O.; SANTOS, S. C. L. dos; VÖLTZ, R. R.; STANGE JUNIOR, E.; KAMINSKI, N. Influência de Guadua aff. paraguayana Doell na estrutura e regeneração de um segmento de Floresta Ombrófila Mista Aluvial, no Alto Tibagi, Paraná. Cerne, Lavras-MG, prelo.

HAAG, H. P.; VALERA, F. P.; CHIARANDA, R.; KIKUTI, P.; CHAVEZ, J. M.; DONALD, E. L. F.; RIZZO, L. T. B.; RUEDA, J. L. Ciclagem de nutrientes em florestas tropicais. Campinas-SP: Fundação Cargill, 1985, 144 p.

INSTITUTO AGRONÔMICO DO PARANÁ (IAPAR). Cartas climáticas do estado do Paraná. Documento 18. Londrina, 1994, 45 p.

INSTITUTO PARANAENSE DE DESENVOLVIMENTO ECONÔMICO E SOCIAL (IPARDES) (http://www.ipardes.gov.br/perfil_municipal/EscolheMun.php), Acesso em: 05/04/2008.

JACOMINE, P. K. T. Solos sob matas ciliares. In: RODRIGUES, R. R.; LEITÃO FILHO, H. de F. (Eds.). Matas ciliares: conservação e recuperação. São Paulo: Edusp Fapesp, p. 27 - 31, 2000.

JENNY, H.; GESSEL, S. P.; BINGHAM, F. T. Comparative study of decomposition rates of organic matter in Temperate and Tropical Regions. Soil Sci., v. 68, p. 419 - 432, 1949.

JORDAN, C. F. Nutrient cycling in tropical forest ecosystems. New York: John Wiley \& Sons Ltd, $1985,190 \mathrm{p}$.

JUDZIEWICZ, E. J.; CLARK L. G.; LONDOÑO, X.; STERN, M. J. American bamboos. Washington, D.C.-USA: Smithsonian Institution Press, 1999, 390 p.

LIMA, W. de P.; ZAKIA, M. J. B. Hidrologia de matas ciliares. In: RODRIGUES, R. R.; LEITÃO FILHO, H. de F. (Eds.). Matas ciliares: conservação e recuperação. São Paulo: Edusp Fapesp, p. 33 - 44, 2000.

MAACK, R. Geografia física do estado do Paraná. 2. ed. Rio de Janeiro: José Olympio, 1981, 450 p.

MALAVOLTA, E. Elementos de nutrição mineral de plantas. São Paulo: Ed. Agronômica Ceres, 1980, $254 \mathrm{p}$.

MARTINS, A. P. L.; REISSMANN, C. B. Material vegetal e as rotinas laboratoriais nos procedimentos químico-analíticos. Scientia Agrária, v. 8, n. 1, p. 1 - 17, 2007. 
MASON, C. F. Decomposição. São Paulo: EPU: Ed. da Universidade de São Paulo, 1980, 63 p.

MELLO, R. S. P. Produção de serapilheira e aspectos da ciclagem de nutrientes em dois tipos florestais adjacentes no Rio Grande do Sul. 136 f. Dissertação (Mestrado em Ciências Biológicas) Universidade Federal do Rio Grande do Sul, Porto Alegre-RS, 1995.

MINERAIS DO PARANÁ S/A (MINEROPAR). Mapa geológico do estado do Paraná. Curitiba: DNPM-MINEROPAR. 1 mapa: color.; 1,97 X 97 cm. Escala 1:650.000, 1989.

MINISTÉRIO DO MEIO AMBIENTE (MMA). Proteção e recuperação da Floresta com Araucárias: Propostas de criação de novas Unidades de Conservação Federais no Paraná e em Santa Catarina. sd.

OHMBERGER, D. The bamboos of the world: annotated nomenclature and literature of the species and the higher and lower taxa. Elsevier, Amsterdam, 1999, 585 p.

OLSON, J. S. Energy storage and the balance of producers and decomposers in ecological systems. Ecology, v. 44, n. 2, p. 322 - 331, 1963.

PRITTCHET, W. L. Suelos forestales: propriedades, conservación y mejoramiento. México: Editorial Limusa, Balderas, 1986, 634 p.

RODRIGUES, R. R.; SHEPHERD, G. J. Fatores condicionantes da vegetação ciliar. In: RODRIGUES, R. R.; LEITÃO FILHO, H. de F. (Eds.). Matas ciliares: conservação e recuperação. São Paulo: Edusp Fapesp, p. $101-107,2000$.

SOUSA, S. G. A. de. Produção e decomposição de serapilheira de uma Floresta Ombrófila Mista Aluvial, rio Barigui, Araucária/PR. 127 f. Tese (Doutorado em Ciências Florestais) - Universidade Federal do Paraná, Curitiba-PR, 2003. 